\title{
Hantavirus: The Next Pandemic We Are Waiting For?
}

\author{
Abbas Khan ${ }^{1} \cdot$ Mazhar Khan ${ }^{2} \cdot$ Saeed Ullah ${ }^{3}$ Dong-Qing Wei ${ }^{1,4,5}$
}

Received: 11 September 2020 / Revised: 19 December 2020 / Accepted: 22 December 2020 / Published online: 24 January 2021

(c) International Association of Scientists in the Interdisciplinary Areas 2021

\begin{abstract}
Hantaviruses, albeit reported more than 40 years ago, are now considered emerging viruses' because of their growing importance as human pathogens. Hantavirus created focal news when the paradoxical spread was reported during the world's pandemic battle of the COVID-19, killing a man in Yunnan province of China, further jeopardizing the existing of the human race on the planet earth. In recent years an increasing number of infections and human-to-human transmission is creating a distressing situation. In this short communication, we have focused on the biology, pathogenesis, immunology, epidemiology and future perspective of the Hantaviruses. Our understandings of hantavirus related pandemics and syndrome are limited, the contributing environmental factors, the cellular and viral dynamics in transmission from natural reservoirs to humans and finally, the virology in humans is quite intricate. Priorities for future research suggest that setting up scientific collaboration, the funding, and encouragement of health ministries and the research institutes should take admirable steps to build an understanding of this virus. Discovering new drugs or other therapeutic molecules such as vaccines takes a longer time. Thus with the recent artificial intelligence (AI) technology, the rifle for impending new medicines should be hastened. Last but not least, a data-sharing platform should be provided where all the researchers should share and make available all the necessary information such as genomics, proteomics, host-factors, and other epigenetics information, which will encourage the research collaboration in the preparation against the Hantaviruses.
\end{abstract}

\section{Graphic Abstract}

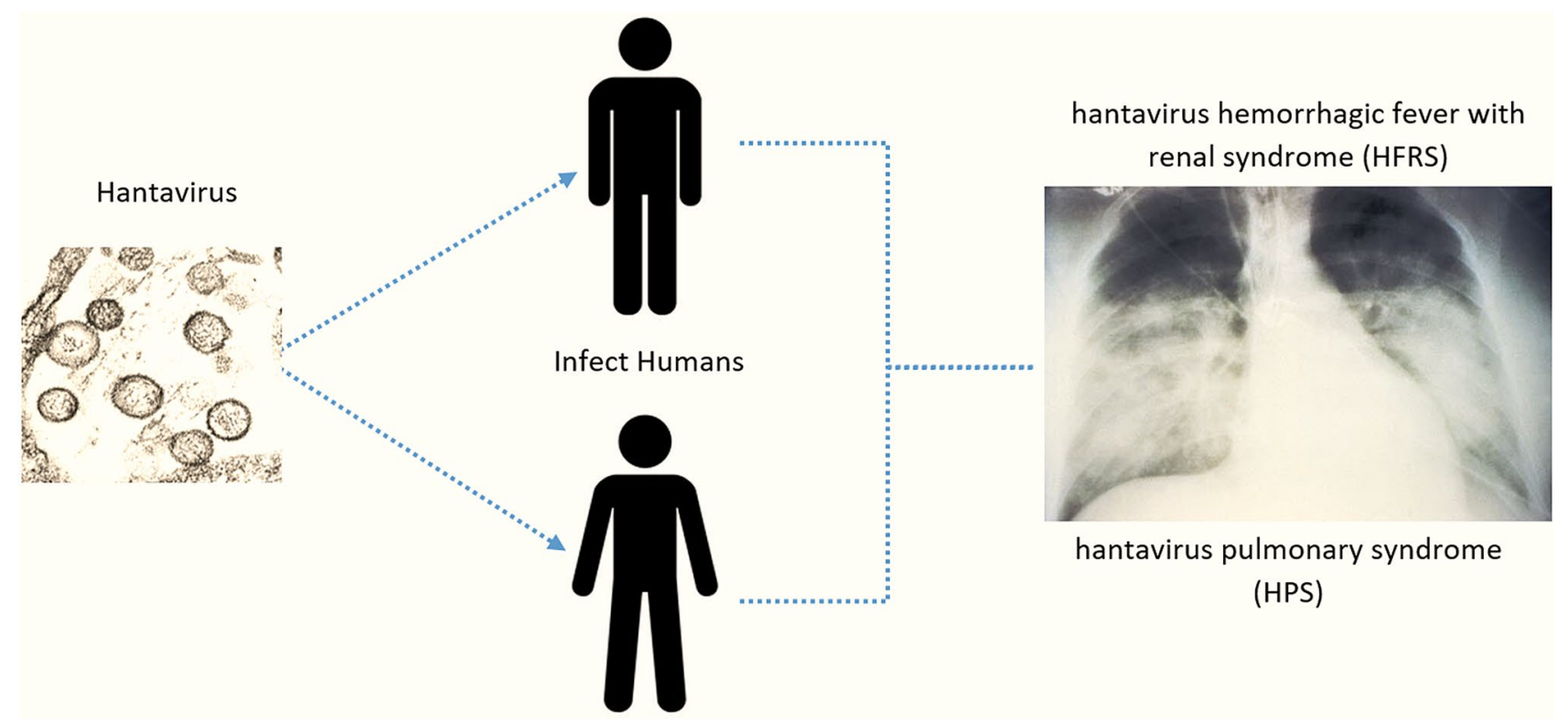

Keywords Hantavirus · Transmission · Immunology · Human-to-human transmission · Artificial intelligence

Extended author information available on the last page of the article 


\section{The Biology of Hantaviruses}

Hantaviruses, albeit reported more than 40 years ago, are now considered emerging viruses' because of their growing importance as human pathogens. [1]. Hantaviruses are single-stranded RNA viruses (negative sense) capable of infecting species (shrews, moles and bats) including humans [2]. They invade the cells through the transmembrane receptors, the integrin's, proliferating in the endothelium, by making the mRNA, proteins and replicating the viral genome-the virion, comprising of genome encapsulated in glycol-ribonucleoprotein capsule, with an integral constituent enzyme RNA-dependent RNA-polymerase (RdRp). The genome of the Hantavirus encodes three essential proteins such as precursor glycoprotein which eventually matures into two mature components known as $\mathrm{Gn}$ and $\mathrm{Gc}$, nucleocapsid (N) protein, and the replicatory machinery $\operatorname{RdRp}[3,4]$. These three segments are called small (S), medium (M), and Large (L) based on their size. The viral polymerase is encoded in the $\mathrm{L}$ segment.

In contrast, the $\mathrm{M}$ and $\mathrm{S}$ elements encode the precursor (GPC) for two viral surface glycoproteins (G1 and G2, or $\mathrm{Gn}$ and $\mathrm{Gc}$ ) and nucleocapsid (N) proteins, respectively[5]. The two different components of the $\mathrm{S}$ glycoprotein (four G1 spikes and four G2 spikes) encoded by the M segment may interact with the $\beta$-integrin and pave the way for the entry of Hantavirus to the host cell[6]. With a C-terminal domain, the two $\mathrm{S}$ glycoproteins form a globular shape with transmembrane helices. This $\mathrm{S}$ protein directly interacts with the $\mathrm{N}$ protein through a conserved Zinc finger (residues 543-599) tail of the G1 component and play a role in the Hantavirus assembly[7]. In supplying natural antiviral defence the primary effector cells of the innate immune response and type I interferons (IFNs) play a pivotal role[8]. To evade from the host response, the production of IFN- $\beta$ is inhibited by the G1 portion of the $S$ glycoprotein of the Hantavirus by binding to TRAF3 and preventing RIG-I/TBK1-directed IRF3 phosphorylation[9]. This phosphorylation of IRF3 is vital in IFN- $\beta$ induction. This potential differentiates pathogenic hantaviruses from non-pathogenic ones, as they are unable to inhibit the induction of IFN- $\beta[10]$.

On the other hand, the primary target of the host immune system is the $\mathrm{N}$ protein which is a small and highly conserved protein among the hantaviruses[11]. The $\mathrm{N}$ protein is a primary detection marker for the diagnosis of Hantavirus' disease[12]. By shaping viral RNPs, the $\mathrm{N}$ protein also defends viral genomic RNA from degradation by the cellular nucleases through encapsulating vRNA (negative-sense genomic) and cRNA (positive sense anti-genomic)[13]. The important role of the $\mathrm{N}$ protein is to interact with the host (Human) $\mathrm{MxA}(\mathrm{p} 78$ ) Protein and forms a MxA-N protein complex and evade the host immune system[14]. The efficiency of Hantavirus replication has been shown to be inversely proportional to the ability of infected cells to enable the expression of MxA. Induction of the type I IFN against the viruses is the primary function of the MxA protein which poses immune resistance against the viral infections[15]. It has been reported that the $\mathrm{N}$ protein of the Hantavirus binds to the MxA protein and this complexes is potentially reported as the mechanism of MxA inhibition and eventually the host immune response[16, 17]. The multi-domain RNAdependent RNA-polymerase is a usual replicatory machinery for the Hantaviruses. Hence, this data suggest that the Hantaviruses possess similar biology to most of the other RNA viruses. Therefore, applying the already practiced technology could aid the development of vaccine and other medications.

\section{The Pathogenesis and Immunology of Hantaviruses}

The Hantavirus reservoir infection hosts are not affected (probably due to immunosuppression of the host), but in humans, it is causing hemorrhagic fevers, including the "hemorrhagic fever with renal syndrome" (HFRS) and "hantavirus cardiopulmonary syndromes" (HCPS)[18]. Pathologically these syndromes are described as aggravated immune reactions having augmented production of cytokines and cytotoxic T lymphocytes, with amplification in the permeability (vascular trickle) of the endothelial cells in the capillaries[19].

Electron micrograph illustrations of hantavirus reveled that it possesses a typical viral architecture, comprised of a genome enclosed in a nucleocapsid with spikes of glycoproteins. The virion is replicated by RNA-dependent RNApolymerases in the host endothelium cells. In due course of infection, the virus particle on attachment to the cell surface through the receptor is endocytosed by the cell, forming a clathrin-coated vesicle. (evidence suggests multiple pathways for the entry of virus particle in the cell [20]. After endocytosis, the virion forms and early endosome and finally the late endosome (a change in $\mathrm{PH}$ triggers this transition) after which the viral ribonucleoproteins are released, and possible the initial transcription occurs at this release site. The viral replication is believed to occur Golgi compartment, from where the newly synthesized virus particles are transported to the cell membrane for budding (Fig. 1) [21].

In humans, the hantavirus infection occurs by inhalation of aerosols contaminated with virus particles from rodent waste or as reported the human to human transmission possible by aerosol or contaminated blood and fluid transmission 
Fig. 1 The schematic representation of viral attachment and multiplication within the host cell. Image adapted from [22]

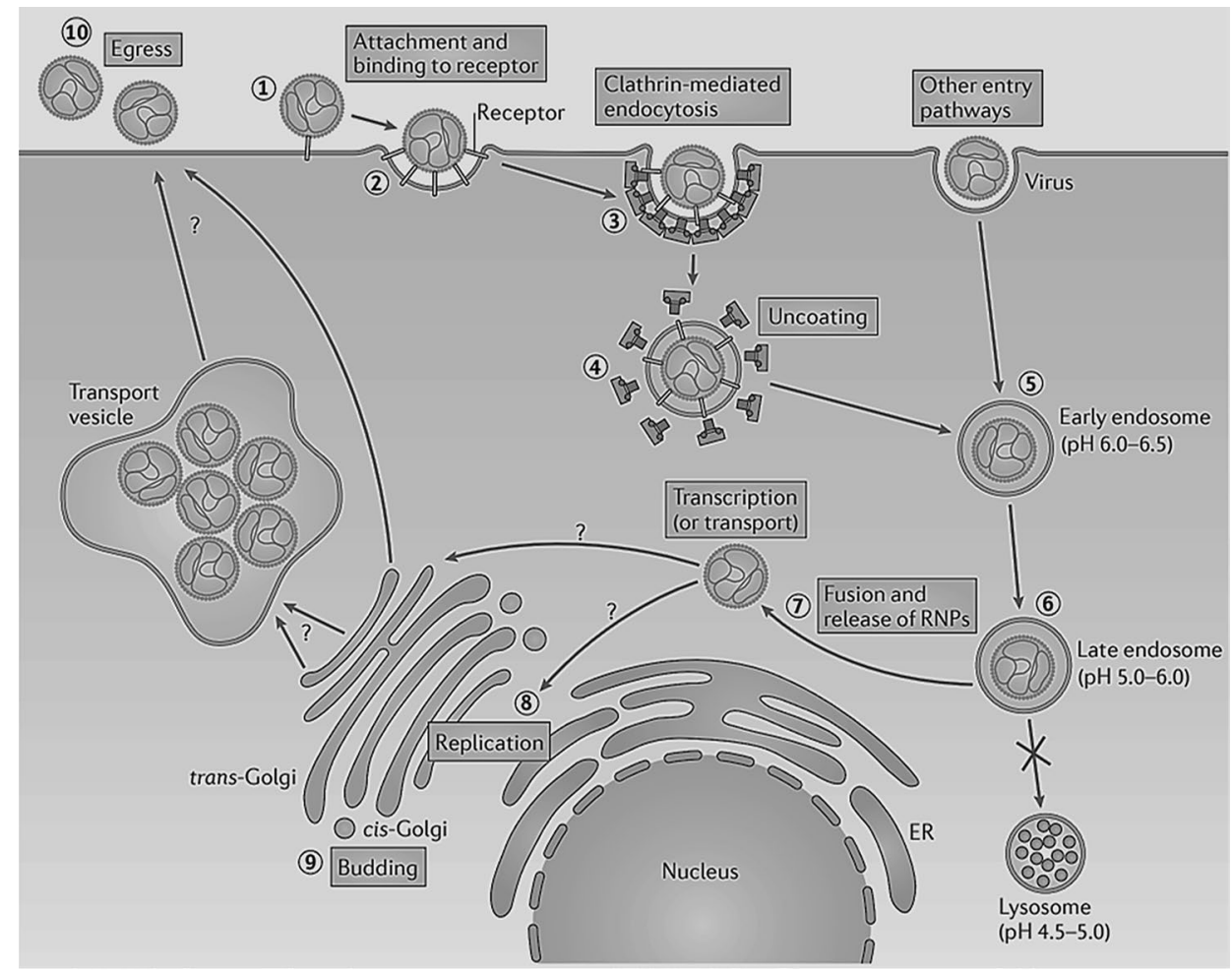

[23]. Like typical viral infections, hantavirus infection is characterized by high fever, body aches and nausea [2, 23], in renal infection Proteinuria, hematuria and nephritis.

Hantaviruses can cause acute or long term infection complications, comprising HFRS \& HCPS, affecting multiple organ systems including cardio-pulmonary, nephritic and neural systems. Upon the infection, immune system activation triggers innate and adaptive responses of variable intensity with either lethal or non-lethal effects. The severity of the infection is also critically dependent on the genotype of the host and the and the strains of the hantavirus. The HFRS follows five distinct phases which are febrile, hypotensive, oliguric, polyuric and convalescent. At the same time, A sudden onset of respiratory failure due to pulmonary oedema and cardiogenic shock, myalgia, cough and diarrhoea is frequently associated with HCPS [3].

The cell surface antigens, human leukocyte antigens (HLAs) responsible for presenting viral associated antigens to $\mathrm{T}$ lymphocytes. The variations in the HLA alleles in different populations were reported to have different severity of infections with different strains of viruses. For example, the Finnish population with particular HLA variants were susceptible to have the most severe form of Puumala virus (PUUV) infection, while in Chinese, Slavonian and in united states populations different threshold of severity in infections with different strains of viruses are reported[24].

Similarly, the immune response generated by different species of hantavirus is different, upon infection and detection by the immune system of the host, secretions of type I interferons (IFNs) IFN- $\beta$ interferons are triggered. In the adaptive immune response, the cytotoxic T lymphocytes, $\mathrm{CD} 4+\mathrm{T}$ lymphocytes and activated plasma B cells activation is elicited. However, the plasma volume of the adaptive immune cells is variable according to different species of the virus (In PUUV infection raised levels of $\mathrm{CD} 8+$ and $\mathrm{CD} 4+\mathrm{T}$ lymphocytes are reported) $[25,26]$.

The adaptive immunity obtained against hantaviruses by the hosts lasts the entire life, and hence there is no relapse of the infection in the lifetime after the primary infection. Correspondingly, the inflammatory symptoms developed in the infection is due to the Cytokines like interleukin-1 (IL-1) IL-6 and tumor necrosis factor (TNF), specifically, the raised levels of IL- 6 are reported to be associated with thrombocytopenia and renal failure. In general, the pathophysiology of hantavirus is a bit diverse and varies according to the genotypes of human populations and strains of the viruses [27]. Hantavirus infection varies in clinical manifestations, variance in illness severity, from mild to extreme, depending on the environmental and physical characteristics of the individual. Therefore, precision-based approaches are the best alternatives to tackle such emerging diseases. 


\section{Epidemiological Perspective}

Hantavirus created focal news when the paradoxical spread was reported during the world's pandemic battle of the COVID-19, killing a man in Yunnan province of China, further jeopardizing the existing of the human race on the planet earth. More than 1,500 cases of HCPS have been documented caused by 15 genetically distinct strains of hantaviruses in the Americas, all correlated with sigmodontine rodents. The lethalness and the gravity of the hantavirus are higher compared to SARs-CoV-2 virus, because of its high death rate of $50 \%$. As in HFRS \& HCPS, the targets are vital organs, including lungs and kidneys. Globally, the reported hantavirus cases in countries including; Germany (2017) 1,713, Canada 109 (with estimated death rate 29\%), and the United States 728 cases (Fig. 2) [28]. Approximately 1,50,000 HFRS cases are estimated to occur worldwide annually. The spread of hantavirus in the Asian countries is also notable and specifically in the People's Republic of China. It is considered a severe public health threat in China because it has been reported in 30 provinces of China. Over the past ten years, 112,177 HFRS cases while 1,116 deaths are reported in China among which $84.16 \%$ are from the only nine provinces. It has also been reported that 10,000 cases were reported in 2014-2015. With these statistics, China is reported to contribute $40-50 \%$ to the worldwide cases [29].
On the other hand, in Russia and South Korea, similar outbreaks are reported with an estimated death rate of $1 \%$ [30, 31]. In Europe, more than 3,000 HFRS cases are diagnosed per year, and this figure continues to grow exponentially. In Europe Puumala Orthohantavirus (PUUV) and Dobrava hantavirus (DOBV) species are the most frequently reported to be involved in human infections. With a case fatality rate of 12 per cent, DOBV is Europe's most lifethreatening hantavirus. It is liable over almost all the fatal HFRS cases in Europe [32, 33]. Since 1995, HCPS has been classified among the notifiable diseases in the United States. Six hundred twenty-four cases of HCPS were registered in the United States during the period 1993-2013. About 100-200 HCPS cases are registered annually in Argentina. During 2013, Chile reported 837 HCPS incidents, with a 36.1 per cent mortality rate. Before 2013, Brazil reported 1,600 cases of HCPS; the number of seropositive patients, nonetheless, is estimated to be much higher. Hantavirus infections are projected to show a steady rise with the rapid growth of cities in South America and increased production of agriculture [34, 35]. In African countries, Hantavirus infections are reported before 2006 [36]. These figures are adequate to alarm the concerns, to implement tangible measures for containment of the disease before its foul ramifications. The most impenetrable scenario is the human-tohuman transmission, reported in 2005 and 2019, having the tendency to cause another global pandemic of more lethal virus compared to the corona virus.

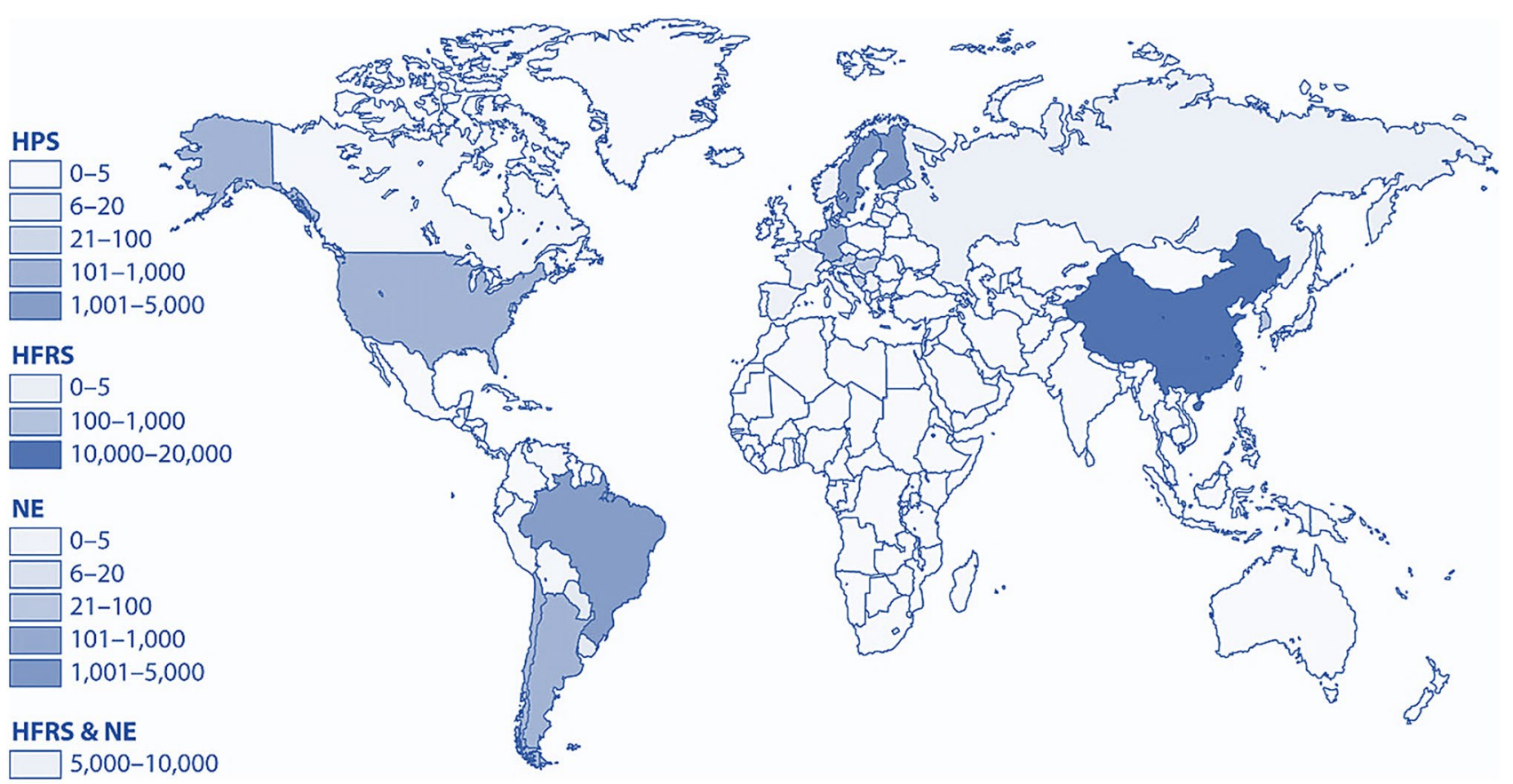

Fig. 2 Geographical illustration and per year country wise incidences reported by Douglas Goodin, Kansas State University[37] 


\section{Future Perspective and Policy Recommendation}

Our understandings of hantavirus related pandemics and syndrome are limited, the contributing environmental factors, the cellular and viral dynamics in transmission from natural reservoirs to humans and finally, the virology in humans is quite intricate. Potentially further serological variants of this virus will be characterized with more than 36 species reported, the diversity in the evolutionary array of these viruses are more diverse.

Before it is too late precautionary measurements should be considered. Setting up scientific collaboration, the funding, and encouragement of health ministries and the research institutes should take admirable steps to build an understanding of this virus. Before the war begins, efforts are explicitly needed to grasp the transmission of this virus from animals to humans and human-to-human, which will eventually help to come up with prevention strategies. As speculated, the Asian population is protected from the severity of recent coronavirus due to the advantage of Bacillus Calmette-Guérin (BCG) vaccination. So, looking into the same nature of diseases, respiratory illness caused by both the hantavirus and coronaviruses, the practice of BCG vaccination throughout the world should be exercised to develop the immune response against such attacks. With these, ecological factors should be identified, which accelerates the transmission and infection. The most important point is to exercise the practice of drug repurposing and other therapeutic agents at first hand. Discovering new drugs or other therapeutic molecules such as vaccines takes a longer time. Thus with the recent artificial intelligence (AI) technology, the rifle for new impending drugs should be hastened. Last but not least, a data-sharing platform should be provided where all the researchers should share and make available all the necessary information such as genomics, proteomics, host-factors, and other epigenetics information, which will encourage the research collaboration in the preparation against the Hantaviruses. In conclusion, genuine efforts are needed to ensure human lives safety and to get ready for the battle against any Hantaviruses outbreak.

\begin{abstract}
Acknowledgements This work is financed by the Ministry of Science and Technology of China, NSFC, STCS (Science and Technology commission of Shanghai), NSFH and SJTU JiTLMDS under the grant numbers 2016YFA0501703, 61832019, 32070662, 32030063, 162300410060, 19430750600 and YG2017ZD14. The computational resources were provided by HPC-SJTU and Pengcheng Laboratory. Dong-Qing Wei received all the financial support.
\end{abstract}

\section{Compliance with Ethical Standards}

Conflict of Interest The authors declare that they have no conflicts of interest.

\section{References}

1. Klempa B (2009) Hantaviruses and climate change. ClinMicrobiol Infect 15(6):518-523. https://doi.org/10.111 1/j.1469-0691.2009.02848.x

2. Van den Bosch M, Bird W (2018) Oxford textbook of nature and public health: The role of nature in improving the health of a population. Oxford Univ Press. https://doi.org/10.1093/ med/9780198725916.001.0001

3. Schmaljohn C, Hasty S, Dalrymple J, LeDuc J, Lee H, von Bonsdorff C, Brummer-Korvenkontio M, Vaheri A, Tsai T, Regnery $\mathrm{H}$ et al (1985) Antigenic and genetic properties of viruses linked to hemorrhagic fever with renal syndrome. Science 227(4690):1041-1044. https://doi.org/10.1126/science.2858126

4. Ferron F, Weber F, de la Torre JC, Reguera J (2017) Transcription and replication mechanisms of Bunyaviridae and Arenaviridae L. proteins. Virus Res 234:118-134

5. Muyangwa M, Martynova EV, Khaiboullina SF, Morzunov SP, Rizvanov AA (2015) Hantaviral proteins: structure, functions, and role in hantavirus infection. Front Microbiol 6:1326

6. Gavrilovskaya IN, Shepley M, Shaw R, Ginsberg MH, Mackow ER (1998) $\beta 3$ integrins mediate the cellular entry of hantaviruses that cause respiratory failure. ProcNatlAcadSci 95(12):7074-7079

7. Estrada DF, De Guzman RN (2011) Structural characterization of the Crimean-Congo hemorrhagic fever virus $\mathrm{Gn}$ tail provides insight into virus assembly. J BiolChem 286(24):21678-21686

8. Finlay BB, McFadden G (2006) Anti-immunology: evasion of the host immune system by bacterial and viral pathogens. Cell 124(4):767-782

9. Yoneyama M, Fujita T (2007) Function of RIG-I-like receptors in antiviral innate immunity. J BiolChem 282(21):15315-15318

10. Alff PJ, Gavrilovskaya IN, Gorbunova E, Endriss K, Chong Y, Geimonen E, Sen N, Reich NC, Mackow ER (2006) The pathogenic NY-1 hantavirus G1 cytoplasmic tail inhibits RIG-I-and TBK-1-directed interferon responses. J Virol 80(19):9676-9686

11. Vapalahti O, Kallio-Kokko H, Närvänen A, Julkunen I, Lundkvist $\AA$, Plyusnin A, Lehvaslaiho H, Brummer-Korvenkontio M, Vaheri A, Lankinen H (1995) Human B-cell epitopes of Puumala virus nucleocapsid protein, the major antigen in early serological response. J Med Virol 46(4):293-303

12. Amada T, Yoshimatsu K, Yasuda SP, Shimizu K, Koma T, Hayashimoto N, Gamage CD, Nishio S, Takakura A, Arikawa J (2013) Rapid, whole blood diagnostic test for detecting antihantavirus antibody in rats. J Virol Methods 193(1):42-49

13. Mir M, Panganiban A (2004) Trimeric hantavirus nucleocapsid protein binds specifically to the viral RNA panhandle. J Virol 78(15):8281-8288

14. Kanerva M, Melén K, Vaheri A, Julkunen I (1996) Inhibition of puumala and tula hantaviruses in Vero cells by MxA protein. Virology 224(1):55-62

15. Pavlovic J, Schröder A, Blank A, Pitossi F, Staeheli P (2007) Mx proteins: GTPases involved in the interferon-induced antiviral state. In: Ciba Foundation Symposium 176-The GTPase Superfamily: The GTPase superfamily: Ciba Foundation Symposium 176: 233-247. doi: https://doi.org/10.1002/9780470514450.ch15

16. Khaiboullina SF, Rizvanov AA, Deyde VM, St. Jeor, S.C, (2005) Andes virus stimulates interferon-inducible MxA protein expression in endothelial cells. J Med Virol 75(2):267-275

17. Kochs G, Janzen C, Hohenberg H, Haller O (2002) Antivirally active MxA protein sequesters La Crosse virus nucleocapsid protein into perinuclear complexes. ProcNatlAcadSci 99(5):3153-3158

18. Muranyi W, Bahr U, Zeier M, van der Woude FJ (2005) Hantavirus infection. J Am SocNephrol 16(12):3669-3679 
19. Van Epps HL, Terajima M, Mustonen J, Arstila TP, Corey EA, Vaheri A, Ennis FA (2002) Long-lived memory T lymphocyte responses after hantavirus infection. J Exp Med 196(5):579-588

20. Lozach P-Y, Mancini R, Bitto D, Meier R, Oestereich L, Överby AK, Pettersson RF, Helenius A (2010) Entry of bunyaviruses into mammalian cells. Cell Host Microbe 7(6):488-499

21. Ramanathan HN, Chung D-H, Plane SJ, Sztul E, Chu Y-K, Guttieri MC, McDowell M, Ali G, Jonsson CB (2007) Dyneindependent transport of the hantaan virus nucleocapsid protein to the endoplasmic reticulum-Golgi intermediate compartment. J Virol 81(16):8634-8647

22. Vaheri A, Strandin T, Hepojoki J, Sironen T, Henttonen H, Mäkelä S, Mustonen J (2013) Uncovering the mysteries of hantavirus infections. Nat Rev Microbiol 11(8):539-550. https://doi. org/10.1038/nrmicro3066

23. Vapalahti O, Mustonen J, Lundkvist Å, Henttonen H, Plyusnin A, Vaheri A (2003) Hantavirus infections in Europe. Lancet Infect Dis 3(10):653-661

24. Deter J, Bryja J, Chaval Y, Galan M, Henttonen H, Laakkonen J, Voutilainen L, Vapalahti O, Vaheri A, Salvador AR (2008) Association between the DQA MHC class II gene and Puumala virus infection in Myodesglareolus, the bank vole. Infect Genet Evolut 8(4):450-458

25. Korva M, Saksida A, Kunilo S, Jeras BV, Avšič-Županc T (2011) HLA-associated hemorrhagic fever with renal syndrome disease progression in Slovenian patients. Clin Vaccine Immunol 18(9):1435-1440

26. Mäkelä S, Mustonen J, Ala-Houhala I, Hurme M, Partanen J, Vapalahti O, Vaheri A, Pasternack A (2002) Human leukocyte antigen-B8-DR3 is a more important risk factor for severe puumala hantavirus infection than the tumor necrosis factor $-\alpha(-308)$ G/A polymorphism. J Infect Dis 186(6):843-846

27. Klingström J, Lindgren T, Ahlm C (2008) Sex-dependent differences in plasma cytokine responses to hantavirus infection. Clin Vaccine Immunol 15(5):885-887
28. Johnson K (2001) Hantaviruses: history and overview. In: Hantaviruses. Springer. DOI: https://doi.org/10.1007/978-3-642-56753 -7_1.pp. 1-14

29. Zhang Y-Z, Zou Y, Fu ZF, Plyusnin A (2010) Hantavirus infections in humans and animals. China Emerg Infect Dis 16(8):1195

30. Garanina S, Platonov A, Zhuravlev V, Murashkina A, Yakimenko V, Korneev A, Shipulin G (2009) Genetic diversity and geographic distribution of hantaviruses in Russia. Zoonoses Public Health 56(6-7):297-309

31. Lee HW (1989) Hemorrhagic fever with renal syndrome in Korea. Rev Infect Dis 11(Supplement_4):S846-S876

32. Vaheri A, Henttonen H, Voutilainen L, Mustonen J, Sironen T, Vapalahti O (2013) Hantavirus infections in Europe and their impact on public health. Rev Med Virol 23(1):35-49

33. Rasmuson J, Andersson C, Norrman E, Haney M, Evander M, Ahlm C (2011) Time to revise the paradigm of hantavirus syndromes? Hantavirus pulmonary syndrome caused by European hantavirus. Eur J ClinMicrobiol Infect Dis 30(5):685-690

34. Control CfD (1993) Prevention: hantavirus infection-southwestern United States: interim recommendations for risk reduction. US Department of Health and Human Services, Public Health Service, Centers

35. Yanagihara R (1990) Hantavirus infection in the United States: epizootiology and epidemiology. Clin Infect Dis 12(3):449-457

36. Klempa B, Fichet-Calvet E, Lecompte E, Auste B, Aniskin V, Meisel H, Denys C, Koivogui L, ter Meulen J, Krüger DH (2006) Hantavirus in African wood mouse, Guinea. Emerg Infect Dis 12(5):838

37. Jonsson CB, Figueiredo LTM, Vapalahti O (2010) A global perspective on hantavirus ecology, epidemiology, and disease. ClinMicrobiol Rev 23(2):412-441

\section{Authors and Affiliations}

\section{Abbas Khan ${ }^{1} \cdot$ Mazhar Khan $^{2} \cdot$ Saeed Ullah ${ }^{3} \cdot$ Dong-Qing Wei ${ }^{1,4,5}$}

Abbas Khan

abbaskhan@sjtu.edu.cn

Dong-Qing Wei

dqwei@sjtu.edu.cn

1 Department of Bioinformatics and Biological Statistics, School of Life Sciences and Biotechnology, Shanghai Jiao Tong University, Shanghai 200240, P.R. China

2 The CAS Key Laboratory of Innate Immunity and Chronic Diseases, Hefei National Laboratory for Physical Sciences at Microscale, School of Life Sciences, CAS Center for Excellence in Molecular Cell Science, University of Science and Technology of China (USTC), Collaborative Innovation Center of Genetics and Development, Hefei 230027, P.R. China
3 Saidue group of Teaching Hospital, Swat, Khyber Pakhtunkhwa, Pakistan

4 State Key Laboratory of Microbial Metabolism, Shanghai-Islamabad-Belgrade Joint Innovation Center on Antibacterial Resistances, Joint Laboratory of International Cooperation in Metabolic and Developmental Sciences, Ministry of Education and School of Life Sciences and Biotechnology, Shanghai Jiao Tong University, Shanghai 200030, P.R. China

5 Peng Cheng Laboratory, Vanke Cloud City Phase I Building 8, Xili Street, Nashan District, Shenzhen, Guangdong 518055, P.R. China 